\title{
Renata Tańczuk
}

\section{AUTOREFLEKSJA I POSTKOLONIALIZM W GRASSI MUSEUM FÜR VÖLKERKUNDE W LIPSKU}

\section{Self-reflection and postcolonialism in GRASSI Museum für Völkerkunde in Leipzig}

\begin{abstract}
Ethnological museums have become subject of research and reflection undertaken by critical studies and cultural anthropology. For several decades there has been ongoing discussion on their colonial past, their relation to art museums, their mission in the age of mass migration, as well as the way they shape the image of non-European communities and cultures and develop systems which classify things.

This paper focuses on an analysis of Werkstatt Prolog (Working Space Prologue) conducted by GRASSI Museum für Völkerkunde in Leipzig and presents the self-reflexive and postcolonial character of the museum. I attempt to answer the following question: can a museum that was founded on the colonial past become a space for intercultural meetings for which a reference to the past will be liberating, not paralyzing?
\end{abstract}

Keywords: self-reflexive museum, postcolonialism, GRASSI Museum für Völkerkunde, Werkstatt Prolog

Muzea etnograficzne stały się przedmiotem badań i refleksji podjętych przez studia krytyczne i antropologię kulturową. Już od kilku dziesiątek lat toczona jest dyskusja nad ich kolonialną przeszłością, relacją do muzeów sztuki, rolą w kształtowaniu etnologii jako akademickiej dyscypliny, wypracowywaniu porządków, według których klasyfikujemy świat rzeczy ${ }^{1}$, i kształtowaniu obrazu społeczności oraz kultur pozaeuropejskich, wreszcie nad ich miejscem na mapie instytucji badawczych i edukacyjnych oraz misją w świecie masowych migracji. Muzeum etnograficzne nastawione na ukazywanie różnorodności kulturowej generuje pytania etyczne dotyczące

1 James Clifford w tekście Kolekcjonując samych siebie przedstawia system klasyfikowania obiektów z kręgu pozaeuropejskiego w kulturze Zachodu (J. Clifford, Kłopoty z kultura. Dwudziestowieczna etnografia, literatura i sztuka, przeł. E. Dżurak et al., Wydawnictwo KR, Warszawa 2000, s. 212-254). 
sposobów pozyskiwania artefaktów, prawa do ich posiadania, przemianowania, tj. zmiany ich statusu, do przedstawiania wizji kultury własnej i innych. Konieczne jest postawienie pytań o to, kto jest autorytetem w przekazywaniu wiedzy o kulturze i jak ten autorytet wpływa na odbiorcę $;$ w jakim stopniu ci, o których kulturze opowiada muzeum, mogą wyartykułować w nim własny punkt widzenia; na ile muzealna wypowiedź jest dobrym przekładem tubylczych znaczeń i wartości; co gubią muzealne przekłady i co zasłania klasyfikacja, a także stosowane do opisu kategorie ${ }^{3}$. Ivan Karp pisze: „Ekspozycja jest w sposób nieunikniony terenem współzawodnictwa. Walka toczy się nie tylko o to, co ma być reprezentowane, ale i o to, kto będzie kontrolował środki reprezentacji. W tej walce wchodzi w grę kontrola nad obiektami i nad trybem ich wystawiania, a ostatecznie artykulacja tożsamości. (...) Ekspozycje są uprzywilejowanymi scenami ukazywania wyobrażenia własnego i wyobrażenia «innego»"4. Jeśli, jak się dziś podkreśla, ,[m]uzeum ma być terenem ścierania się różnorodnych wizji rzeczywistości, swoistym miejscem negocjacji światopoglądowych", to czy istnieje możliwość przekroczenia kulturowych uprzedzeń, stereotypów, przekonań i przed-sądów w procesie tworzenia ekspozycji i czy każde stanowisko światopoglądowe jesteśmy gotowi (i czy powinniśmy) dopuścić do głosu ${ }^{6}$ Czy zbudowane na kolonialnej przeszłości muzeum może stać się przestrzenią międzykulturowych spotkań, dla których odniesienie do przeszłości będzie wyzwalające, a nie paraliżujące? Czy można w nim ustanowić nowe relacje między podmiotami społeczno-kulturowymi, relacje partnerstwa, równych pozycji, dialogu? ${ }^{7}$

W Niemczech od 2000 roku toczy się szczególnie ożywiona dyskusja, która przekroczyła mury akademii. Muzea stały się tu przedmiotem publicznych i politycznych debat, również za sprawą ważnych wydarzeń ${ }^{8}$ i ekspozycji muzealnych zrealizowa-

2 Zob. A. Wieczorkiewicz, Czyja jest kultura, czyje jest muzeum? Muzealne interpretacje kultury, „Kultura i Społeczeństwo” 2000, nr 4, s. 177.

3 Interesująco te kwestie rozważa Anna Wieczorkiewicz (ibidem, s. 179-180).

$4 \quad$ I. Karp, Culture and Representation, w: I. Karp, S.D. Lavine (red.), Exhibiting Cultures: The Poetics and Politics of Museum Display, Smithsonian Institution Press, Washington-London 1991, s. 15, za: A. Wieczorkiewicz, op. cit., s. 185.

A. Wieczorkiewicz, op. cit., s. 193.

6 Zob. ibidem, s. 193.

7 Zob. K. Maniak, Pozaeuropejskie dziedzictwo kulturowe w europejskim muzeum - strategie (re)prezentacji, „Prace Etnograficzne” 2015, t. 43, z. 2, s. 72-92, http://www.ejournals.eu/pliki/art/6334/ (dostęp: 27.07.2019).

8 W 2004 roku przypadła setna rocznica krwawego stłumienia antykolonialnego powstania w dzisiejszej Namibii. W 2005 roku natomiast przypadła rocznica wybuchu tzw. powstania Maji Maji w Niemieckiej Afryce Wschodniej. Rocznice wywołały dyskusje wśród badaczy i aktywistów nad kolonialną przeszłością Niemiec, zainicjowały wydarzenia i publikacje. W 2015 roku rząd Niemiec uznał kolonialną wojnę w Namibii za ludobójstwo i podjął negocjacje w sprawie odszkodowań. Na temat toczonej w Niemczech dyskusji zob. L. Förster, F. Von Bose, Concering Curatorial Practice in Ethnological Museums: An Epistemology of Postcolonial Debates, w: Ph. Schorch, C. McCarthy (red.), Curatopia: Museums and the Future of Curatorship, Manchester University Press, Manchester 2019, s. 44-56. 
nych w Weltkulturen Museum we Frankfurcie czy w Deutsches Historisches Museum w Berlinie ${ }^{9}$, a ostatnio wielkiego muzealnego projektu, jakim jest Humboldt Forum, który miał zostać sfinalizowany w bieżącym roku ${ }^{10}$. Utworzenie Humboldt Forum, uważanego za „najambitniejszy projekt kulturalny”, kosztuje 595 milionów euro i wywołuje kontrowersje nie tylko z powodu kosztów. Oto w odbudowanym po zniszczeniach wojennych pałacu, symbolu niemieckiej i pruskiej imperialnej przeszłości, mają zostać ulokowane berlińskie zbiory między innymi z Ethnologisches Museum i Museum für Asiatische Kunst, które zostały zgromadzone w erze kolonialnej ${ }^{11}$.

Zerwanie z kolonialną przeszłością etnograficznych muzeów przybiera niekiedy charakter symbolicznej zmiany ich nazwy, na przykład dziś mamy w Wiedniu „Weltmuseum” („Muzeum Świata”), we Frankfurcie nad Menem „Museum Fünf Kontinente” („Muzeum Pięciu Kontynentów”) czy w Bazylei „Museum der Kulturen” („Muzeum Kultur”). Choć zmiana imienia nie jest pozbawiona znaczenia, to jednak nade wszystko istotne są określone działania na rzecz zmiany praktyk wystawienniczych, przekształcenia ustalonych kategorii, porządków klasyfikacyjnych, włączenia do współpracy społeczności indygenicznych, a także restytucja zagrabionych obiektów i szczątków ludzkich, gromadzonych również w tych placówkach ${ }^{12}$.

Przyjrzyjmy się, jak z niektórymi z postawionych tutaj problemów radzi sobie GRASSI Museum für Völkerkunde w Lipsku. Jak sądzę, można je uznać za jedno z bardziej autorefleksyjnych muzeów etnograficznych, które w swojej działalności zarówno akcentuje przeszłość - także kolonialną - swoich zbiorów, jak i ukazuje problematyczność klasyfikacji muzealnych, poddaje refleksji europejską dominującą pozycję oglądu Innego, kwestionuje ujęcie kultur jako wysp z wyraźnie wyzna-

9 Chodzi o działania podjęte przez Clémentine Deliss w latach 2010-2015 (zob. Postcolonial Museum Laboratory: Clémentine Deliss in conversation with Joanna Sokotowska, „Widok” 2014, nr 7, s. 1-11, także w: K. Maniak, op. cit.) oraz o wystawę German Colonialism: Fragments Past and Present z 2016 roku.

10 Siedziba Humboldt Forum będzie znajdować się w odbudowywanym Berliner Schloss, pałacu niemieckich władców i cesarzy, pamiętającym czasy piętnastowiecznych Hohenzollernów. Podczas II wojny światowej pałac poważnie ucierpiał, a władze komunistyczne dokończyły dzieła zniszczenia, decydując w 1950 roku o rozbiórce ruin, aby 20 lat później wybudować w tym samym miejscu Pałac Republiki, służący m.in. jako siedziba parlamentu NRD (otwarty w roku 1976, zburzony w 2008).

11 Jak dowiadujemy się z internetowych zapowiedzi, Humboldt Forum ma wskrzesić niektóre z idei berlińskiej Kunstkammery, mieszczącej się w dawnym Stadtschloss, „,będąc miejscem badania świata”, ,gdzie sztuka i nauka kreatywnie się splatają” (https:/www.humboldtforum.com/en/pages/ humboldt-forum [dostęp: 15.05.2019])

12 Kwestia restytucji została podjęta na międzynarodowej konferencji Sensitive Heritage: Ethnographic Museums and Material/Immaterial Restitutions zorganizowanej przez GRASSI Museum für Völkerkunde w Lipsku w grudniu 2018 roku. W konferencji uczestniczyli badacze i pracownicy instytucji naukowych i muzealnych oraz przedstawiciele różnych grup narodowych i etnicznych z Afryki, Australii i Nowej Zelandii. Debata toczyła się wokół problemów związanych z restytucją materialnego i niematerialnego dziedzictwa, badania proweniencji oraz uczynienia z restytucji metody etnograficznej. 
czonymi granicami, a jednocześnie zwraca uwagę na przepływy ludzi, rzeczy, znaczeń i wartości. Stara się też oddać głos przedmiotom jako głównym narratorom i sprawcom muzealnego przekazu. Istotne jest również otwarcie przestrzeni muzeum na eksplorację zbiorów i ich artystyczne interpretacje przez tych, których obiekty muzeum posiada, poszukiwanie postkolonialnej strategii funkcjonowania w czasach masowych migracji.

Początki lipskiego Museum für Völkerkunde związane są z kolekcją Friedricha Gustava Klemma (1802-1867), historyka kultury, pioniera etnologii, którego koncepcja kultury stała się podstawą stworzenia pierwszej antropologicznej definicji kultury Edwarda B. Tylora. Po jego śmierci władze Lipska i Saksonii oraz przedstawiciele uniwersytetu toczyli spory o przyszłość jego zbiorów i cenę, jaką należałoby za nie zapłacić. $Z$ powodu braku porozumienia skonfliktowanych stron w 1869 roku zawiązał się lokalny komitet, który pod przewodnictwem dr. med. Bernharda Hermanna Obsta (późniejszego pierwszego dyrektora muzeum) zdołał zebrać datki w wysokości 3000 marek i nabyć główną część kolekcji (również British Museum zakupiło liczne obiekty ze zbiorów Klemma). Przez kolejne lata kolekcja znacząco się powiększyła, także dzięki donacjom licznych przyjaciół, mecenasów i sponsorów, wśród których znalazł się słynny odkrywca Troi, Heinrich Schliemann. W latach 1892-1895, dzięki donacji Franza Dominica Grassiego (1801-1880), kupca pochodzenia włoskiego, zostało zbudowane Grassimuseum, w którego murach znalazło się Muzeum Sztuk i Rzemiosła oraz, wcześniej rozproszone, Muzeum Etnografii. Oba muzea dynamicznie się rozwijały i szybko rosła liczba pozyskiwanych przez nie obiektów, dlatego w latach 1925-1929 zbudowano Nowe Muzeum Grassi. Niestety na skutek bombardowań w 1943 i w 1945 roku uległo ono poważnym zniszczeniom. Szczęśliwie zbiory przetrwały działania wojenne dzięki wcześniejszej ewakuacji. W latach powojennych podjęto prowizoryczne naprawy uszkodzonej budowli, jednak awaria systemu grzewczego sprawiła, że po 1981 roku muzeum na kilka lat prawie całkowicie przerwało swoją działalność. Dopiero po zjednoczeniu Niemiec podjęto prace rekonstrukcyjne, umożliwiające jego ponowne otwarcie jako znane nam dziś GRASSI Museum, które mieści Museum für Völkerkunde (Muzeum Etnograficzne), Museum für Angewandte Kunst (Muzeum Sztuki Użytkowej) oraz Museum für Musikinstrumente (Muzeum Instrumentów Muzycznych) ${ }^{13}$.

Dla wizji muzeum, podejmowanych przez nie działań, realizowanej misji niezwykle ważna jest osoba dyrektora. Tak się szczęśliwie złożyło, że 1 lutego 2015 roku dyrektorką lipskiego Museum für Völkerkunde została Nanette Jacomijn Snoep z Holandii. Właściwie Snoep została jednocześnie dyrektorką trzech etnograficznych

13 Zob. https://www.freshmuseum.com/artpage/grassimuseumfuerangewandtekunst (dostęp: 30.07.2019); https://www.skd.museum/en/visit/grassi-museum-leipzig/ (dostęp: 15.05.2019); M.E. Menninger, Städtische Kunstförderung, w: U. von Hess, M. Schäfer in Verbindung mit W. Bramke und P. Listewnik, Unternehmer in Sachsen: Aufstieg - Krise - Untergang - Neubeginn, Leipziger Studien zur Erforschung von regionenbezogenen Identifikationsprozessen 4, Leipziger Universitätsverlag, Leipzig 1998, s. 103. 
muzeów oraz wiceprezeską Staatliche Kunstsammlungen Dresden (SKD). Stało się tak, ponieważ do Drezdeńskich Państwowych Zbiorów Sztuki w 2010 roku dołączyły Staatliche Etnographische Sammelungen Sachsen (SES, Państwowe Zbiory Etnograficzne) obejmujące GRASSI Museum für Völkerkunde w Lipsku, Museum für Völkerkunde w Dreźnie i Völkerkundemuseum w Herrnhut. W ten sposób powstała druga co do wielkości w Niemczech kolekcja etnograficzna obejmująca 350000 obiektów, 200000 dokumentów obrazowych i 350000 pozycji bibliotecznych.

Nanette J. Snoep studiowała antropologię i zarządzanie w kulturze ${ }^{14}$. Przed rozpoczęciem pracy w Lipsku była główną kuratorką Musée du Quai Branly w Paryżu (otwarte w 2006 roku). W powstanie tego muzealnego projektu Jacques'a Chiraca ${ }^{15}$ była zaangażowana od 1999 roku. Była odpowiedzialna między innymi za zawartość wystawy muzealnej i inwentarz 300000 obiektów. W 2005 roku została kierowniczką Działu Historycznego, w którym zajmowała się restauracją i cyfrową inwentaryzacją kolekcji oraz jej zachowaniem, rozwojem i ostatecznym przeniesieniem do muzeum. Niezwykle ważne, jak sądzę, dla sposobu myślenia o muzeum etnograficznym było jej doświadczenie zdobyte przy przygotowaniu słynnej wystawy z 2011 roku w Quai Branly: Exhibitions. L'invention du sauvage (29.11.2011-3.06.2012), na którą pozyskała obiekty z ponad 200 muzeów na świecie, co spotkało się z wielkim uznaniem. We współpracy z dyrektorem Palais de Tokyo w Paryżu utworzyła w 2012 roku podróżującą wystawę Les Maîtres du Désordre, łączącą etnografię z nowoczesną i współczesną sztuką. W 2014 roku w Strasburgu otwarto zaplanowaną przez nią stałą wystawę w Musée Vodou, należącym do francuskich kolekcjonerów Marie Luce i Marca Arbogastów. Hartwig Fischer, dyrektor generalny SKD, postawił przed Snoep między innymi zadanie, ,wprowadzenia dialogu pomiędzy europejskimi i nieeuropejskimi zbiorami, a przede wszystkim rozwoju zbiorów etnograficznych (...) i stworzenia możliwości wykorzystania ich wielkiego potencjału"16.

W jednym z wywiadów ${ }^{17}$, który przeprowadziła z nową dyrektorką Anette Rein, Nanette Snoep, opowiadając o swojej wizji muzeum, podkreślała konieczność zmia-

14 Informacje o N.J. Snoep podaję za: Nanette Jacomijn Snoep Appointed New Director of the State Ethnographic Collections of Saxony, http://artdaily.com/news/76088/Nanette-Jacomijn-Snoep-appointed-new-Director-of-the-State-Ethnographic-Collections-of-Saxony (dostęp: 27.07.2019).

15 Na otwarciu muzeum w 2006 roku Chirac mówił o pobudkach politycznych, które legły u podstaw stworzenia muzeum. Chodziło o oddanie „,sprawiedliwości kulturom pozaeuropejskim. (...) Francja pragnie oddać hołd tym, którym przez lata historia zdawała gwałt. (...) Chodzi o to, aby uznać miejsce, jakie ich wytwory artystyczne zajmują w naszym dziedzictwie; uznać nasz dług wobec społeczeństw, w których powstały. (...) Zerwać z ignorancją i pogardą, przywrócić godność” (cyt. za: A. Trąbka, Muzeum etnograficzne jako sposób opowiadania o innych kulturach. Przypadek muzeów paryskich, „Prace Etnograficzne. Zeszyty Naukowe Uniwersytetu Jagiellońskiego” 2010, t. 38, s. 135, http:// www.ejournals.eu/pliki/art/504/ [dostęp: 27.07.2019]).

16 Nanette Jacomijn Snoep Appointed...

17 A. Rein, Little Stories with Big Impact: An interview with Nanette Jacomijn Snoep, „ExpoTime!” 2015 (July/August), s. 16-20, https://www.bundesverband-ethnologie.de/kunde/assoc/15/pdfs/ Rein-2015-Interview-Nanette-J.-Snoep.pdf (dostęp: 27.07.2019). 
ny sposobu patrzenia na świat z punktu widzenia zachodniego „my” - „My, te tzw. muzea etnologiczne, stale interpretujemy świat w kategoriach europejskich wartości i doświadczeń" ${ }^{18}$, a istnieją przecież inne perspektywy, z których możemy świat zobaczyć - oraz stworzenia sytuacji międzynarodowego dzielenia się:

Siedzimy na światowym dziedzictwie ludzi spoza Europy, często zebranym w kontekście dominacji. Dlatego musimy współpracować i dzielić się wiedzą o naszych kolekcjach z ludźmi niebędącymi Europejczykami, z Afryki, Azji, Ameryki, Pacyfiku, z intelektualistami, artystami, duchownymi z całego świata. Chcemy współpracować z interesującymi nieeuropejskimi myślicielami i twórcami, którzy nie potrzebują oficjalnego dyplomu, żeby być przyjętymi w naszych muzeach na równych prawach. Te debaty o międzynarodowej współpracy i partnerstwie zaczęły się już w latach 90., ale w 2015 roku powinniśmy w końcu w systematyczny i fundamentalny sposób wprowadzić je w praktykę ${ }^{19}$.

Snoep uznała również za konieczne zniesienie dychotomii etnologii i sztuki, która jest ograniczająca, oraz połączenie różnych dyscyplin humanistycznych, myślenie włączające, a nie ograniczające i wyłączające. Mówiła:

Musimy pokazać w naszym muzeum historyczny proces globalizacji, historię spotkań z różnych perspektyw. Będziemy musieli uwydatnić różne sposoby widzenia świata i związki, kolizje poglądów na świat, wielorakie konfrontacje różnych rodzajów lokalnych historii. Muzeum, które buduje mosty i pyta, w jaki sposób inne wizje i wiedza były przez wieki adaptowane, adoptowane, odrzucane, integrowane lub ignorowane. Takie jest moje pragnienie ${ }^{20}$.

Podkreślała także potrzebę opowiadania biografii zebranych obiektów, nie tylko przypisanie im etnograficznego znaczenia. W tym kontekście pojawiła się w rozmowie refleksja nad ,autentycznością”, która stanowi swego rodzaju fetysz etnograficznego, i nie tylko, muzeum. Odpowiedź na pytanie, co stanowi o autentyczności obiektu, staje się ważne, jeśli uwzględnimy oczywiste wzajemne wpływy, inspiracje kultur, na przykład czy ,słynne mink-isi, nabite gwoździami, obdarzone mocą rzeźby z Kongo, które już w latach 80. XIX wieku przystosowano do europejskiego gustu"21, są autentycznie kongijskie. Snoep dostrzegła braki w kolekcjach etnologicznych nie ma w nich obiektów współczesnych, takich jak ,nowoczesne rytualne maski i kostiumy, ponownie wynajdywane [reinvented] tradycje"22.

Pozwolę sobie przytoczyć dość obszerną wypowiedź Snoep, która wyraża jej wizję muzeum etnograficznego:

(...) musi [ono - przyp. R.T.] być miejscem, gdzie interkulturowy dialog powinien być rozumiany jako proces dwukierunkowy. To musi się wydarzyć we wszystkich naszych analizach obiektów, pojęciach i poglądach.

$18 \quad$ Ibidem, s. 16.

19 Ibidem.

20 Ibidem.

21 Ibidem, s. 17.

22 Ibidem. 
Jako muzeum musimy unikać tzw. etnograficznej teraźniejszości. Kiedy pokazujemy obiekty, musimy przemieścić je w czasie i przestrzeni. Dlatego musimy na każdej etykiecie podawać czas, w którym obiekt był stworzony lub używany, a jeśli nie mamy tej informacji, to przynajmniej czas, w którym ten obiekt został pozyskany lub kiedy dostał się do muzeum. To samo dotyczy autora: jeśli go nie znamy - w kolekcjach etnologicznych prawie zawsze tak jest - powinno się na etykiecie podawać: „autor niezidentyfikowany”.

Wzmianka o ,anonimowym autorze” już jest informacją i uniknięciem „etnograficznej anonimowości”. W ten sposób można uniknąć kilku pułapek wywodzących się z czasów kolonialnych oraz kilku wynikających z naszej współczesnej etnocentryczności.

Powinno się zastosować nową systematyzację informacji: 1) autor/własność; 2) czas i miejsce wytworzenia; 3) wyjaśnienia dotyczące wcześniejszego użycia przedmiotu; 4) czas i kontekst pozyskania; oraz ostatnie, ale nie mniej ważne: 5) dodatkowa informacja o biografii obiektu wyrażona przez: opowieści o pierwszym właścicielu, opowieści o kontekście pozyskania, historie o jego podróży aż do gabloty, opowieści o jego kolekcjonerze itd. ${ }^{23}$

Przedstawienie osobistych indywidualnych historii obiektu, a nie tylko obiektywnego opisu etnograficznego, pozwala zwiedzającemu lepiej go zrozumieć, znosi egzotyzujący dystans, pobudza uczucia, pomaga odkryć wspólnotę ludzkich doświadczeń: „,elem jakiejkolwiek muzealnej działalności wystawienniczej powinno być mediowanie porównywalnych, powszechnych doświadczeń i emocji ludzkiego życia. Konieczne jest budowanie mostów między ludźmi z Saksonii i na przykład ludźmi w Nigerii, aby mogli rozwinąć dla siebie empatię. Chcę zaproponować subiektywne osobiste historie, aby poruszyć zwiedzających na poziomie emocjonalnym"24.

Pod koniec 2018 roku Nanette J. Snoep przestała być dyrektorką GRASSI Muzeum i objęła takie samo stanowisko w Rautenstrauch-Joest-Museum Kulturen der Welt w Kolonii. Na jej miejsce zatrudniono Léontine Meijer-van Mensch, także Holenderkę, która była dyrektorką programową Muzeum Żydowskiego w Berlinie i zastępcą dyrektora od 1 lutego 2017 do 31 stycznia 2019 roku. W jakim stopniu opisana powyżej koncepcja Snoep będzie kontynuowana, to się dopiero okaże.

Przyjrzyjmy się teraz realizowanemu w GRASSI Muzeum projektowi Warsztat Prolog (Werkstatt Prolog) - zainicjowanemu przez byłą już dyrektorkę - który swoją pierwszą odsłonę jako Prolog\#1-10. Opowiadania ludzi, rzeczy i miejsc miał w grudniu 2016 roku w drezdeńskim Museum für Völkerkunde w Pałacu Japońskim. Warsztat Prolog w Lipsku jest kontynuacją tego wcześniejszego „eksperymentu” i ma być przygotowaniem do przyszłej ekspozycji stałej, która zostanie otwarta w 2022 roku. Jak głosi ulotka opisująca projekt, muzeum w kolejnych miesiącach będzie podejmować „,zagadnienia dotyczące tożsamości, rasizmu, alienacji, biografii obiek-

23 Ibidem, s. 18.

24 Ibidem. 
tów, historii kolekcji, obchodzenia się z ludzkimi szczątkami, relacji Północ-Południe, globalnej nierówności i restytucji”"25. Podjęcie tych kwestii wyraźnie wskazuje na wysoki stopień autorefleksji tej instytucji.

W GRASSI Muzeum miałam okazję być w ubiegłym roku dwukrotnie, najpierw $\mathrm{w}$ lipcu, a następnie $\mathrm{w}$ grudniu. W przeciągu tych kilku miesięcy nastąpiły kolejne odsłony w ekspozycji Warsztat Prolog, pojawiły się nowe opisy, obiekty, filmy, a także nowe formy angażowania publiczności. Niektóre fragmenty widzianej wcześniej ekspozycji zostały uzupełnione. Nie będę tu omawiała każdego elementu wystawy. Zwrócę uwagę tylko na trzy jej aspekty: refleksję nad kolonialną przeszłością muzeum i zarazem drogą obiektów do muzeum oraz nad restytucją dóbr, problem klasyfikacji muzealnej i tworzenia ekspozycji oraz konceptualizację „My/Ja”.

\section{Kolonialne źródła muzeum i restyłucja dóbr}

Na wystawę wkraczamy, mijając między innymi po jednej stronie gablotę z kaskiem kolonialnym, a po drugiej lustro. Pojawiają się pytania, które będą towarzyszyły nam przez cały czas: „Kim Ty jesteś? Kim My jesteśmy?”. Uszczegółowienie tych pytań pozostawia się w pewnym stopniu zwiedzającemu, ale możemy zauważyć, że zbiorowy podmiot, o którego tożsamość zadaje się pytanie, to z pewnością też wspólnota kolekcjonująca (etnologowie, muzeum), a także mieszkańcy Lipska, Niemcy, Europejczycy.

Bez zamorskich wypraw odkrywczych, a następnie bez kolonialnej ekspansji Europejczyków, także Niemców, zbiory lipskiego muzeum nie byłyby tak obfite. Ich symbolem jest kolonialny kask. Obiekty przywożone z ekspedycji badawczych i handlowych, łupy wojenne, a także przedmioty kolekcjonowane, kupowane i otrzymywane od ludów tubylczych zasilały zbiory tej placówki. Imperium niemieckie posiadało od 1884 roku kolonie w Afryce, Chinach i Oceanii. Jest to, jak można przeczytać na stronie internetowej Warsztatu, „trudna historia tych kolekcji. Powstaje pytanie, jak dziś muzeum radzi sobie z tą bolesną historią. Pozbawione głosu obiekty, które tu pokazujemy, skrywają złożone historie z przeszłości" ${ }^{26}$. W kolejnych salach wystawa odnosi się do tych historii. Na stronie projektu przypomniano o krwawej kolonialnej obecności Niemców, przede wszystkim w Afryce: „W niemieckiej Afryce Południowo-Zachodniej w 1904 roku doszło do buntu Herero i Nama, który skończył się pierwszym ludobójstwem XX wieku i zabiciem ponad 90000 ludzi”"27. Szczątki, między innymi zamordowanych Herero, zapełniły zbiory niemieckich uniwersyte-

25 Cytat z ulotki dla zwiedzających. Zob. także: http://prolog-ausstellung.info/about-1 (dostęp: 27.07.2019).

26 Zob. http://prolog-ausstellung.info/zuwemhastdugehoert (dostęp: 27.07.2019).

27 Zob. http://prolog-ausstellung.info/sammelwut (dostęp: 27.07.2019). 
tów i muzeów ${ }^{28}$. W 2018 roku w Berlinie dokonano restytucji szczątków 27 członków Herero i Nama.

Związek Muzeów Państwowych Zbiorów Sztuki w Dreźnie w październiku 2017 roku zwrócił Hawajczykom trzy czaszki i szczękę, które zagrabiono z jaskiń grobowych $^{29}$. W osobnej sali, stanowiącej część omawianej ekspozycji, można zobaczyć film z tej pierwszej saksońskiej restytucji szczątków ludzkich, usłyszeć wypowiedzi przedstawicieli muzeum i natywnych Hawajczyków, którzy mówią o znaczeniu tego aktu. W ten sposób muzeum zarówno przypomina o swojej mrocznej historii, jak i pokazuje, w jaki sposób usiłuje się z nią rozliczyć.

Kwestia restytucji obiektów muzealnych dotyczy nie tylko szczątków ludzkich. Ich zwrot jest obecnie powszechnie akceptowany ${ }^{30}$. Zupełnie inaczej wygląda sytuacja innych obiektów, o które upominają się dziś ludy indygeniczne. I do tych kontrowersji odnosi się także lipskie muzeum, zarówno na wystawie, jak i podczas zorganizowanej w 2018 roku konferencji międzynarodowej, dotyczącej tzw. wrażliwego dziedzictwa w muzeach ${ }^{31}$. Na wystawie ta kwestia została bezpośrednio podjęta w odniesieniu do benińskich brązów, których olbrzymi zbiór jest posiadaniu muzeum w Lipsku i Dreźnie (ponad 200 obiektów). Na ekspozycji zaprezentowano fotografię Williama Downinga Webstera, brytyjskiego handlarza obiektami etnograficznymi i kolekcjonera, jednego z beneficjentów brutalnej grabieży benińskiego skarbca w 1897 roku. Historia brązów benińskich w muzeach europejskich jest tematem na

28 Warto przytoczyć zamieszczoną na stronie Warsztatu informację na temat szczątków ludzkich w muzeach sakońskich: „GRASSI Museum für Völkerkunde w Lipsku, Museum für Völkerkunde w Dreźnie, Völkerkundemuseum w Herrnhut, przechowują liczne ludzkie szczątki. Kilka tysięcy z nich jest częścią tzw. «Kolekcji Antropologicznej», która znajduje się obecnie w Museum für Völkerkunde w Dreźnie. Zbiór ten, będący dziedzictwem epoki kolonialnej, opierał się na rasowych teoriach z XIX i początku XX wieku, a także związany był z wprowadzeniem nowych pozytywistycznych metod badawczych, takich jak kraniometria (badanie czaszki), w celu uzyskania porównywalnych danych na temat ludzkości. Przedstawiciele ówcześnie jeszcze młodej nauki antropologii uważali, że różnice kulturowe między ludźmi można przypisać przyczynom biologicznym. Utworzyli wielkie zbiory kości, aby mieć do dyspozycji wystarczającą ilość materiałów badawczych i porównawczych. Zlecano kolekcjonerom, podróżnikom i poszukiwaczom przygód pozyskiwanie nieeuropejskiego «materiału badawczego» - jak go wtedy nazywano - i przysyłanie go do muzeów i uniwersytetów w Niemczech. Plądrowanie grobów i kontekst przemocy, która wówczas towarzyszyła pozyskiwaniu ludzkich szczątków, są obecnie przedmiotem ostrej krytyki” (http://prolog-ausstellung. info/restitution [dostęp: 27.07.2019]).

29 Ibidem.

30 W praktyce jest to często długotrwały, żmudny proces, niejednokrotnie wywołujący protesty i powodujący wtórną traumatyzację autochtonów domagających się zwrotu przodków.

31 Zob. https://stadtgeselle.wordpress.com/2018/11/13/join-the-conference-about-sensitive-heritage-ethnographic-museums-and-material-immaterial-restitutions-in-leipzig-12-13-12-2018/ (dostęp: 27.07.2019). W związku z problemem restytucji i dekolonizacji muzeów bardzo ważne jest oświadczenie wydane 6 maja 2019 roku podczas dorocznej konferencji dyrektorów muzeów etnograficznych krajów niemieckojęzycznych w Heidelbergu: Decolonising Requires Dialogue, Expertise and Support-The Heidelberg Statement, https://www.musethno.uzh.ch/dam/jcr:101bb5ec-cc0c-4014-afd777974f9e8e03/20190506\%20Heidelberg\%20Statement.pdf (dostęp: 27.07.2019). 
osobną opowieść. W tym miejscu warto zaznaczyć, że muzeum w Lipsku zarówno pokazuje historię tej części swojej kolekcji, jej dokumentowania i eksponowania w latach 1920, 1963, 1980, 1986, 2001, 2016, jak i, za sprawą dokumentalnego filmu z Benin-City z 2018 roku, informuje o znaczeniu tych zbiorów dla współczesnych Nigeryjczyków i ich dążeniu do odzyskania skarbu. Zwrot tego zbioru jest oczywiście przedmiotem ożywionych debat publicznych, ponieważ ma on wielką wartość finansową. Echa tych dyskusji prezentowane są w dostępnych dla zwiedzającego wyimkach z prasy niemieckiej. Na stronie internetowej Warsztatu Projekt podano informację o drodze benińskiego skarbca królewskiego do Europy oraz dość enigmatycznie odniesiono się do kwestii restytucji: „Nasze dwa muzea saksońskie w Dreźnie i Lipsku są odpowiedzialne za to, aby tę historię opowiadać i wspólnie z nigeryjskimi badaczami i instytucjami znaleźć nowy sposób obchodzenia się z tym trudnym dziedzictwem"32. Jak można przypuszczać, zwrot Nigeryjczykom ich dziedzictwa nadal nie jest najbardziej oczywistym sposobem obchodzenia się z nim.

Kilka gablot przeznaczono także na łupy wojenne: włócznie, łuki i tarcze związane z powstaniem Maji-Maji, które miało miejsce w lipcu 1905 roku w Niemieckiej Afryce Wschodniej. Jego przyczyną było wprowadzenie pogłównego, podatku „od głowy”, przez który zubożali autochtoni częściej stawali się robotnikami przymusowymi i musieli zmieniać tereny swoich upraw. Znamienne są dane podane na stronie Warsztatu:

180000 ludzi padło ofiarą tego konfliktu zbrojnego, więc populacja zmniejszyła się o jedną trzecią. Dla porównania, po stronie niemieckiej zginęło 15 żołnierzy i 450 askari - żołnierzy afrykańskich (...). Niemcy skonfiskowali podczas tego konfliktu tzw. łup wojenny. Uznano go za własność państwową i początkowo wysłano do centralnego magazynu w Dar es Salaam. Königliche Museum für Völkerkunde w Berlinie zostało o tym poinformowane przez Departament Kolonialny Ministerstwa Spraw Zagranicznych. W związku z tym muzeum wysłało Karla Weule, wcześniejszego dyrektora Museums für Völkerkunde w Lipsku, który odbywał podróż badawczą po niemieckiej Afryce Wschodniej, aby przejrzał ten łup wojenny. Weule wybrał 500 strzał, 1300 włóczni, 100 łuków oraz bębenki i pasy do amunicji, które wysłał do Berlina w sześciu skrzyniach ${ }^{33}$.

Część łupu trafiła w 1907 roku również do kolekcji lipskiej.

Problem kolonializmu podjęty został także za sprawą filmu - zmontowanej sekwencji zdjęć zrobionych podczas niemieckiej wyprawy do Afryki Środkowej w latach 1907-1908. Na kolejnych fotografiach obrysowano postaci Niemców, uczestników wyprawy, których obcość i władza w ten sposób zostają wyraźnie podkreślone. Film, jak wskazują autorzy wystawy, ,przekazuje widzom nie tylko część historii Niemiec, lecz także historię kolonializmu wraz z jego globalnymi skutkami oraz postępy w dziedzinie etnologii na początku XX wieku"34.

32 Zob. http://prolog-ausstellung.info/sammelwut (dostęp: 27.07.2019).

33 Ibidem.

34 Zob. http://prolog-ausstellung.info/fremd (dostęp: 27.07.2019). 


\section{Klasyfikacja, produkcja wiedzy i praca muzeum}

Kolejnym tematem tej autorefleksyjnej wystawy jest problem losów obiektów muzealnych, kwestia systemów klasyfikacyjnych i generalnie praca muzeum. „Muzealna kuchnia" pokazywana jest na wystawie na kilka różnych sposobów. W jednej z sal wyeksponowano skrzynie ze słuchawkami, z których można usłyszeć głos obiektów opowiadających swoje historie. Mówią one o:

indywidualnych, zbiorowych, lokalnych i globalnych historiach. Opowiadają o kontekście, w jakim były stworzone, używane, a w końcu zebrane, sklasyfikowane i umieszczone w witrynach. Nie tyle przedstawiają one ducha jakiejś społeczności, ile jej pozostałości. Biografie tych obiektów na zawsze pozostaną niedokończone. Dlatego w tej pierwszej części Prologu staraliśmy się oddać im głos, przemienić - zainspirowani historycznymi archiwami - nieme obiekty w podmioty opowiadające swe historie. Ich szepty przypominają nam, że każdy przedmiot, czy to schowany w jednej ze skrzyń, czy wystawiony w witrynie, kryje w sobie niewyobrażalny skarb opowieści o świecie, skądkolwiek i stąd ${ }^{35}$.

Ta część wystawy znów przypomina o kolonialnej przeszłości, ale również o sposobach obchodzenia się z rzeczami przez muzeum. Wiele z nich pozostaje w muzealnych magazynach i czeka na prezentację na wystawie.

Rzecz w muzeum jest przedmiotem działań renowacyjnych, pielęgnacyjnych, źródłem wiedzy naukowej, obiektem klasyfikowanym zgodnie z różnego rodzaju kryteriami i paradygmatami wiedzy, wreszcie obiektem ekspozycyjnym wpisywanym w narrację muzealną. Te elementy prac z i nad obiektem ukazywane są w części Warsztatu odsłaniającej kulisy pracy muzealnej. Główną kwestią dla tej części wystawy jest pytanie o biografię muzealną rzeczy, która trafia do tej instytucji, oraz o to, jak muzeum zmienia jej status i w jaki sposób muzealnicy kształtują nasze jej postrzeganie. Jak już wspomniano, zmiana statusu i kształtowanie sposobu postrzegania obiektu wiążą się z systemami klasyfikacyjnymi stosowanymi do porządkowania zbioru i kształtowania narracji muzealnej. Działanie tego systemu i jego problematyczność dobrze przedstawiono w części zatytułowanej „taxoMania”. W gablotach poukładano różne rodzaje przedmiotów. Podobne do nich zwiedzający będzie mógł zobaczyć także w innych częściach wystawy. Znajdzie tu również kapelusz, który był bohaterem filmu opowiadającego o jego konserwacji, a który można było obejrzeć we wcześniejszej sali. W związku z tą częścią ekspozycji - współczesnym gabinetem osobliwości, w którym pojawiają się próby wprowadzenia porządku przez grupowanie poszczególnych eksponatów - stawiane jest pytanie: czy to się da uporządkować? Można też zapytać, co jest gromadzone i dlaczego właśnie to stanowi obiekt naszego zainteresowania. Przyglądając się pracy muzeum od kuchni, nie sposób też nie zapytać, po co właściwie zbieramy, jaki jest sens tego trwającego od wieków gromadzenia, które w różnych okresach przybierało formę agonu, także ekonomicznego.

35 Zob. http://prolog-ausstellung.info/kistengefluester (dostęp: 27.07.2019). 


\section{Ja i Oni / My i Oni}

Muzeum etnograficzne jest przestrzenią konfrontowania się z kulturowo obcym, a zarazem przestrzenią samopoznania. Poznajemy siebie, konstruując różnicę, przekształcając Obcego w obiekt poznania, eksponując to, co inne, przy czym owa inność jest także naszym konstruktem. Czy Obcy jest takim, jakim go w przestrzeni muzealnej przedstawiliśmy, czy może jest to tylko Obcy z naszej wyobraźni? Spuścizną badań antropologii fizycznej i etnologicznych wypraw są tysiące fotografii antropometrycznych i typów ras. Ten zbiór uzupełniają także zdjęcia robione przybyszom do Europy, delegacjom itp. Wkraczając na wystawę Warsztat, przechodzimy przez ścianę przeźroczystych przesłon, na których wyświetlane są fotograficzne portrety przedstawicieli kultur nieeuropejskich. Pochodzą one z okresu od końca XIX do lat 30. XX wieku i są przechowywane w muzeach Drezna i Lipska. Służyły do typologizacji i klasyfikacji ludzi na podstawie ich fizjonomii, ale także ubioru i ozdób ${ }^{36}$. Wielokrotnie wyświetlane jest też pytanie: „Kim jesteś?”. Ta konfrontacja z portretami innych i pytanie o to, kim jestem, skłania do myślenia zarówno o tym, jak to jest, gdy się jest obiektem badań, jak i o to, co nas łączy. W portretach Obcych usiłujemy znaleźć również własne oblicze - istot przemijających, po których także pozostaną dziesiątki fotografii. W kolejnej odsłonie Warsztatu fotografie Innych możemy oglądać w szufladach szafki. Zarówno zgromadzone w muzeum przedmioty, jak i fotografie ludzi są, jak głosi ulotka, „milczącym świadectwem stałego krążenia po świecie rzeczy, ludzi i idei. Czy jesteśmy w stanie pozwolić im mówić?” I - zapytajmy - co mogą nam dziś powiedzieć o sportretowanych, o ich biografiach? Ta część wystawy, zatytułowana „Kim jesteś?”, „stawia w centrum przedmiot etnologii - byt ludzki - i podejmuje próbę biograficznej rekonstrukcji" ${ }^{37}$. Europejskie spojrzenie uczyniło z Innego, kulturowo obcego, egzotycznego, prymitywnego, przedmiot misji cywilizacyjnej i dominacji. Konstruowanie różnicy jest tworzeniem obrazu Obcego z własnych mitów i kategorii poznawczych. Jedna z części wystawy konfrontuje nas z obrazami Obcego, którym dla innych jesteśmy również my sami. Zwiedzający wystawę ma okazję nie tylko zobaczyć się w ustawionym krzywym zwierciadle, ale może również przyjrzeć się przedstawieniom Europejczyków wykonanym przez przedstawicieli kolonizowanych kontynentów. Możemy zobaczyć, ,jak ci tak zwani «obcy» postrzegali przez stulecia «swoich obcych», europejskich misjonarzy, żołnierzy, kupców, urzędników kolonialnych i podróżników" "38. Jednocześnie możemy też postawić pytanie, jak zmienia się nasz sposób patrzenia na Obcych, także w przestrzeni muzealnej, oraz na nas samych.

Jednym z elementów ekspozycji jest pokój, w którym znajdujemy przedmioty wiążące się z obecnością nowych mieszkańców Saksonii. Są to uchodźcy, migranci,

\footnotetext{
36 Zob. http://prolog-ausstellung.info/werbistdu (dostęp: 27.07.2019).

37 Ibidem.

38 Zob. http://prolog-ausstellung.info/fremd (dostęp: 27.07.2019).
} 
którzy w Niemczech znajdują swój nowy dom. Część wystawy pod tytułem „My?”, będąca rezultatem badań przeprowadzonych wśród uchodźców, stawia pytanie o tożsamość kultury saksońskiej, o to, jak się ona zmienia za sprawą przybyszów. Zwiedzający może wejść do salonu, przed którym wita go gipsowy krasnal. Można w nim, jak piszą autorzy ekspozycji, „zobaczyć i usłyszeć historie, fragmenty obserwacji saksońskich rytuałów, wydarzeń i miejsc. Jest to kolaż anegdot, stereotypów, doświadczeń, nieporozumień i kuriozów. «My?» opowiada o spotkaniu uchodźców z pewnym nowym społeczeństwem"39.

Podczas mojego pierwszego pobytu w muzeum GRASSI w sali poświęconej wizerunkom Obcego można było zobaczyć pięciominutowy film Clary Wieck Mouseion, ukazujący gabloty muzealne ze strojami kobiecymi, fetysze z muzeum, stół z globusem i książkami, a także znane nam z mediów sceny przekraczania granic przez migrantów. Na stronie informującej o filmie można znaleźć opis przesłania tego artystycznego projektu, który stanowi komentarz do sytuacji zwiedzania i funkcjonowania muzeum etnograficznego dziś:

Muzeum jako sanktuarium Muz: szukając Muzy Instytucji, „biały człowiek” przechodzi przez sale wystawowe muzeum etnograficznego. Zapraszany do reagowania na eksponowane przedmioty, konfrontuje się ze swoimi lękami, pragnieniami, gloryfikacjami i projekcjami. Na zewnątrz muzeum ludzie podczas ucieczki przed dronami są filmowani i przenoszeni na ekrany telewizyjne jako obiekty historyczne. Mouseion łączy świat muzeum ze światem zewnętrznym. W ten sposób muzeum staje się przestrzenią myślenia i asocjacji, w której kwestionowane są tradycyjne dychotomie. Jest to również porównanie punktów widzenia: tu zwiedzający muzeum ogląda nieme obiekty, reprezentujące różne społeczności i historie o międzyprzestrzeniach, o pertraktacjach, ucieczce lub komunikacji pomiędzy światem tym i tamtym, a tam, po drugiej stronie, ludzie stoją za rzeczami, które stworzyli ${ }^{40}$.

Przemierzając sale Museum für Völkerkunde w Lipsku, kroczymy przez historię tej instytucji, jednocześnie przyglądamy się sposobowi, w jaki konfrontuje się ona ze swoją przeszłością, działalnością i publicznością. Czy omawiany projekt przekształca lipskie muzeum w instytucję w pełni autorefleksyjną i zarazem postkolonialną? Sądzę, że możemy pozytywnie odpowiedzieć na to pytanie, nawet jeśli weźmiemy pod uwagę, że praca nad trudną przeszłością nie jest zakończona. Jeśli, jak sugerują Gurdun Dahl i Ronald Stade, muzeum postkolonialne powinno ,przedmiotem swojego zainteresowania uczynić także życie uchodźców, nielegalnych emigrantów czy imigrantów poszukujących pracy i włączyć obiekty dokumentujące ich życie do swoich ekspozycji”"41, to muzeum GRASSI, jak widzieliśmy, podejmuje te problemy, przygotowując się do nowego otwarcia stałej wystawy. Rozwija również współpracę z tymi, których obiekty znajdują się w jego zbiorach, udostępniając im przestrzeń dla

39 Zob. http://prolog-ausstellung.info/wir (dostęp: 27.07.2019).

40 Zob. https://grassi-voelkerkunde.skd.museum/nl/ausstellungen/archiv/grassi-invites-2/clara-wieck/ (dostęp: 27.07.2019)

41 G.B. Dahl, R. Stade, Anthropology, Museum and Contemporary Cultural Process, „Ethnos” 2000, nr 2, za: A. Trąbka, op. cit., s. 138. 
własnej narracji o tożsamości, przeszłości i współczesności oraz o złożonych relacjach ze współczesnym zachodnim światem. Świadectwem tego była także wystawa Megalopolis. Głosy z Kinszasy ${ }^{42}$ (dostępna od 1 grudnia 2018 do 14 kwietnia 2019 roku), prezentująca twórczość 24 kongijskich artystów, którym muzeum udostępniło swoją przestrzeń i zbiory.

\section{Bibliografia}

Clifford J., Kolekcjonując samych siebie, w: J. Clifford, Kłopoty z kulturą. Dwudziestowieczna etnografia, literatura i sztuka, przeł. E. Dżurak et al., Wydawnictwo KR, Warszawa 2000, s. 212-254.

Dahl G.B., Stade R., Anthropology, Museum and Contemporary Cultural Process, „Ethnos” $2000, \mathrm{nr} 2$.

Förster L., Bose F. Von, Concering Curatorial Practice in Ethnological Museums: An Epistemology of Postcolonial Debates, w: Ph. Schorch, C. McCarthy (red.), Curatopia: Museums and the Future of Curatorship, Manchester University Press, Manchester 2019, s. 44-56.

Karp I., Culture and Representation, w: I. Karp, S.D. Lavine (red.), Exhibiting Cultures: The Poetics and Politics of Museum Display, Smithsonian Institution Press, Washington-London 1991.

Maniak K., Pozaeuropejskie dziedzictwo kulturowe w europejskim muzeum - strategie (re)prezentacji, „Prace Etnograficzne” 2015, t. 43, z. 2, s. 72-92, http://www.ejournals.eu/pliki/ art/6334/ (dostęp: 27.07.2019).

Menninger M.E., Städtische Kunstförderung, w: U. von Hess, M. Schäfer in Verbindung mit W. Bramke und P. Listewnik, Unternehmer in Sachsen: Aufstieg - Krise - Untergang - Neubeginn, Leipziger Studien zur Erforschung von regionenbezogenen Identifikationsprozessen 4, Leipziger Universitätsverlag, Leipzig 1998, s. 97-105.

Postcolonial Museum Laboratory: Clémentine Deliss in conversation with Joanna Sokołowska, ,Widok” 2014, nr 7, s. 1-11.

Rein A., Little Stories with Big Impact: An interview with Nanette Jacomijn Snoep, „ExpoTime!” 2015 (July/August), s. 16-20, https://www.bundesverband-ethnologie.de/kunde/ assoc/15/pdfs/Rein-2015-Interview-Nanette-J.-Snoep.pdf (dostęp: 27.07.2019).

Tańczuk R., Megalopolis. Głosy z Kinszasy, „Format. Pismo Artystyczne” 2019, nr 82-83, s. $152-153$.

Trąbka A., Muzeum etnograficzne jako sposób opowiadania o innych kulturach. Przypadek muzeów paryskich, „Prace Etnograficzne. Zeszyty Naukowe Uniwersytetu Jagiellońskiego" 2010, t. 38, s. 135, http://www.ejournals.eu/pliki/art/504/ (dostęp: 27.07.2019).

Wieczorkiewicz A., Czyja jest kultura, czyje jest muzeum? Muzealne interpretacje kultury, „Kultura i Społeczeństwo” 2000, nr 4, s. 177-198.

42 Zob. https://grassi-voelkerkunde.skd.museum/fr/ausstellungen/megalopolis-1-stimmen-aus-kinshasa/ (dostęp: 27.07.2019). Na temat tej wystawy zob. R. Tańczuk, Megalopolis. Głosy z Kinszasy, „Format. Pismo Artystyczne" 2019, nr 82-83, s. 152-153. 


\section{Źródła internetowe:}

Decolonising Requires Dialogue, Expertise and Support - The Heidelberg Statement, https:// www.musethno.uzh.ch/dam/jcr:101bb5ec-cc0c-4014-afd7-77974f9e8e03/20190506\%20 Heidelberg\%20Statement.pdf (dostęp: 27.07.2019).

Nanette Jacomijn Snoep Appointed New Director of the State Ethnographic Collections of Saxony, http://artdaily.com/news/76088/Nanette-Jacomijn-Snoep-appointed-new-Director-of-the-State-Ethnographic-Collections-of-Saxony (dostęp: 27.07.2019).

https://www.humboldtforum.com/en/pages/humboldt-forum (dostęp: 15.05.2019).

https://www.freshmuseum.com/artpage/grassimuseumfuerangewandtekunst (dostęp: 30.07.2019). https://www.skd.museum/en/visit/grassi-museum-leipzig/ (dostęp: 15.05.2019).

http://prolog-ausstellung.info/about-1 (dostęp: 27.07.2019).

http://prolog-ausstellung.info/fremd (dostęp: 27.07.2019).

http://prolog-ausstellung.info/kistengefluester (dostęp: 27.07.2019).

http://prolog-ausstellung.info/sammelwut (dostęp: 27.07.2019).

http://prolog-ausstellung.info/werbistdu (dostęp: 27.07.2019).

http://prolog-ausstellung.info/wir (dostęp: 27.07.2019).

http://prolog-ausstellung.info/zuwemhastdugehoert (dostęp: 27.07.2019).

http://prolog-ausstellung.info/restitution (dostęp: 27.07.2019).

https://grassi-voelkerkunde.skd.museum/nl/ausstellungen/archiv/grassi-invites-2/clara-wieck/ (dostęp: 27.07.2019).

https://grassi-voelkerkunde.skd.museum/fr/ausstellungen/megalopolis-1-stimmen-aus-kinshasa/ (dostęp: 27.07.2019).

https://stadtgeselle.wordpress.com/2018/11/13/join-the-conference-about-sensitive-heritage-ethnographic-museums-and-material-immaterial-restitutions-in-leipzig-12-13-12-2018/ (dostęp: 27.07.2019). 